\title{
Measuring indirect economic impacts arising from transportation investment by a SCGE model
}

\author{
T. Miyagi, M. Nishimura \& S. Mitui \\ Faculty of Regional Studies, Gifu University, Japan
}

\begin{abstract}
The purpose of this paper is threefold. First, we present a regionally disaggregated CGE model, in which "a region" is defined as a sub-area or a zone within a country or a particular area and the spatial dimension of the economy is explicitly included. In such a spatial CGE model, the estimation of interzonal trade flows has a critically important role: with the presence of shipping cost, suppliers would impose the cost on their sales prices for covering that cost, which changes the product shipping pattern for each type of commodity or service and thereby affects the efficiency of regional economies. Second, we propose a new approach that links travel delay (attributable to congestion) and business productivity. Transportation investment changes the relative economic advantage that each region has through the changes in accessibility to material/service markets and labour markets. To estimate the rate return on transportation investment to reduce congestion, it is necessary to estimate how the specialized transportation policy to reduce congestion has economic impacts on regional economies. Finally, we explore the values of economic impacts measured by an application of the model to Tokai ring road project, which is an on-going project to build an expressway of about $160 \mathrm{~km}$ in length connecting annularly many cities in Tokai region.
\end{abstract}

Keywords: SCGE model, interregional trade coefficients, assessment of transportation investment, accessibility, spatial relative advantage.

\section{Introduction}

Miyagi [1, 2] proposed three types of calibration procedures for SCGE models according to availability of benchmark equilibrium dataset. We call Miyagi's 
model M-SCGE hereafter and briefly review it in the next section. Among those approaches, this paper treats the second case where each of regional input-output table in the nation is assumed to be given. Since in such a spatial CGE model estimation of interregional trade flows has a critical important role, this paper pays a special attention to modelling of interregional trade flows. The basic framework of modelling interregional trade employed here is parallel to the author's previous work [3-5], however, the concept of spatial comparative advantage to account for changes in accessibility is based on the author's recent work $[1,2]$.

SCGE models proposed so far [3-8] have been tried to link transport cost to production efficiency through operating transport margin. The impact on transportation cost arising from changes in the physical network will be assessed by using a transportation model like a traffic assignment technique. The problem is how to integrate those changes in transportation cost into a framework of SCGE model. Margin-commodities including transportation and trade services are regarded as only an appropriate source to reflect the linkage between transportation cost and production function. The margin rate for each type of commodity is available when one can use input-output accounts at purchase price. In Japan, each prefecture makes her own input-output table every five years, however, published input-output tables are all those at production price based. So we have no way to access information on the margin rate of commodities. In addition, the margin-rate conveys information on freight flows, not on passenger transport and other business services. We need to take into account a broad range of impacts arising from changes in accessibility. A discussion on how it becomes possible to model interregional flows of goods and services based on accessibility measures is shown in the third section.

Finally, in fourth section we show applications of the SCGE model to the TokaiI ring road that is an on-going expressway project at Tokai region. For this purpose, the benchmark equilibrium dataset was constructed based on regional input-output tables of 47 prefectures for the year 2000. Input-output tables of distant prefectures from the project were aggregated into a single input-output table; for prefectures included in Tokai region each input-output table at prefecture level was divided into tables at smaller zones. The resultant dataset comprises of 28 regions (or zones) and 8 industrial sectors.

\section{Calibration policies in M- SCGE model}

Table 1 shows a two region input-output table, where each variable represents a value in monetary-terms, being denoted by a letter with tilde (a quantity-based variable is denoted by a letter without tilde). For a convenience purpose of referencing in the later analysis, we divide the interregional IO table shown in table 1 into five sections; section A corresponds to interregional transactions; sections $\mathrm{B}$ and $\mathrm{C}$ represent column and row sums of A-table, respectively. Section D corresponds to an aggregate input-output table for a whole country and section E stands for foreign exchanges. Section B includes each of regional input-output tables and section $\mathrm{C}$ represents the total of regional exports to other 
regions. Foreign trade is assumed to be exogenously given in the closed economy model. On the other hand, the open economy model treats imports from other countries with being endogenously determined as a function of interregional demands. Notation used in the succeeding paragraphs obeys to those used in Table 1.

When demonstrating calibration of SCGE models, we may encounter at least three different cases according to the availability of benchmark dataset.

Case I: Only an aggregated, single input-output data at national level is available. In this case, the forecasting of $\mathrm{A}, \mathrm{B}$ and $\mathrm{C}$ sections is required given a single, aggregate $\mathrm{D}$ table as a benchmark equilibrium data. In order to make this work feasible, we need at least estimated products of all industrial sectors at every region.

Table 1: $\quad$ Interregional input-output table in value-based.

\begin{tabular}{|c|c|c|c|c|c|c|c|c|c|}
\hline & $\begin{array}{l}\text { Zone } \\
\mathbf{r}\end{array}$ & $\begin{array}{l}\text { Final } \\
\text { dem. }\end{array}$ & $\begin{array}{l}\begin{array}{l}\text { Zone } \\
\text { s }\end{array} \\
\end{array}$ & $\begin{array}{l}\text { Final } \\
\text { dem. }\end{array}$ & $\begin{array}{l}\text { Sub- } \\
\text { Tol. }\end{array}$ & $\begin{array}{l}\text { Final } \\
\text { dem. }\end{array}$ & $\operatorname{Exp}$ & Imp & Products \\
\hline \multirow[t]{2}{*}{ Zone $\mathbf{r}$} & $\tilde{x}_{i j}^{r r}$ & $\tilde{d}_{i}^{r r}$ & $\tilde{x}_{i j}^{r s}$ & $\tilde{d}_{i}^{r s}$ & $\tilde{x}_{i j}^{r \cdot}$ & $\tilde{d}_{i}^{r \cdot}$ & $\tilde{E}_{i}^{r}$ & $\tilde{M}_{i}^{r}$ & $\tilde{X}_{i}^{r}$ \\
\hline & $\tilde{v}_{j}^{r r}$ & & $\tilde{v}_{j}^{r s}$ & & $\tilde{v}_{j}^{r \cdot}$ & & & & $\tilde{V}_{j}^{r \cdot}$ \\
\hline \multirow[t]{2}{*}{ Zone $\mathrm{s}$} & $\tilde{x}_{i j}^{s r}$ & $\tilde{d}_{i}^{r r}$ & $\tilde{x}_{i j}^{s s}$ & $\tilde{d}_{i}^{s s}$ & $\tilde{x}_{i j}^{s \cdot}$ & $\tilde{d}_{i}^{s \bullet}$ & $\tilde{E}_{i}^{s}$ & $\tilde{M}_{i}^{s}$ & $\tilde{X}_{i}^{s}$ \\
\hline & $\tilde{v}_{j}^{s r}$ & & $\tilde{v}_{j}^{s s}$ & & $\tilde{v}_{j}^{s \cdot}$ & & & & $\tilde{V}_{j}^{s \cdot}$ \\
\hline $\begin{array}{l}\text { Sub- } \\
\text { total }\end{array}$ & $\tilde{x}_{i j}^{\cdot r}$ & $\tilde{D}_{i}^{r}$ & $\tilde{x}_{i j}^{\cdot s}$ & $\tilde{D}_{i}^{s}$ & $\tilde{X}_{i j}$ & $\tilde{D}_{i}$ & $\tilde{E}_{i}$ & $\tilde{M}_{i}$ & $\tilde{X}_{i}$ \\
\hline $\begin{array}{l}\text { Value- } \\
\text { added }\end{array}$ & $\tilde{V}_{j}^{r}$ & & $\tilde{V}_{j}^{s}$ & & $\tilde{V}_{j}$ & & & & \\
\hline products & $\tilde{X}_{j}^{r}$ & & $\tilde{X}_{j}^{s}$ & & $\tilde{X}_{j}$ & & & & \\
\hline
\end{tabular}

Case II: Each regional input-output table is available. The only work needed in this case is to estimate interregional trade coefficients consistent with given input-output data of each region.

Case III: A complete set of interregional input-output accounts is available.

The former two approaches may be categorized into a non-survey method [6] in the context of the conventional regional models. However, our approach is more sophisticated than traditional non-survey techniques in the sense that all coefficients associated with regional input-output tables and behavioural parameters included in functions used are simultaneously determined in a consistent way with a general economic equilibrium.

\section{Basic structure of M-SCGE model}

While the M-SCGE model is characterized by a way of modelling interregional trade, it has basically the same core structure as can be seen in other CGE models. The M-SCGE basically consists of four main equation systems that determine demand and supply relations, price structure equations, interregional 
trade balances, and market clearing conditions. For production, firms are assumed to use fixed proportion combinations of intermediate inputs and primary factors in the first level; in the second level, CES production is assumed to allow substitutions between regionally produced and imported intermediate inputs from other regions for intermediate inputs, and between capital and labour for primary factors. At the third level, a bundle of imports from other regions is decomposed into input by each regional source using trade model. Household demand structure is also expressed based on a nested CES preference function where regional products and imported goods are identified and distinguished by their shipping-locations. Foreign export is assumed to be exogenously given, and imports from foreign countries are endogenously determined as a function of regional intermediate and final demands in the open economy model. Among the main equation systems, details about the interregional trade model together with the potential function are discussed in this section. In addition, the market clearing conditions are also addressed in relation to free-time.

\subsection{Interregional trade model}

Let us first start with the interregional trade model proposed by Miyagi and Honbu [3, 4] and Miyaga et al. [5]. Consider a country divided into a set of regions (or zones) $R=\{1, \cdots, r, s, \cdots, N\}$ where each region has a set of industrial sectors (or firms) $I=\{1, \cdots, i, j, \cdots, n\}$. Assume that transaction price $p_{i}^{r s}$ of commodity $i \in I$ produced at region $r \in R$ and purchased at region $s \in R$ is ad valorem:

$$
p_{i}^{r s}=p_{i}^{r}\left(1+\eta_{i}^{r s}\right),
$$

where $p_{i}^{r}$ is the production price of commodity $\mathrm{i}$ at region $\mathrm{r}$ and $\left\{\eta_{i}^{r s}\right\}$ represents mark-up factors associated with activities of transport. It is assumed that firms in each zone produce output with the following constant elasticity (CES) of production function:

$$
z_{i}^{s}=\left[\sum_{r \in R}\left(\theta_{i}^{r}\right)^{\frac{1}{\sigma_{t}}}\left(x_{i}^{r s}\right)^{\frac{\sigma_{t}-1}{\sigma_{t}}}\right]^{\frac{\sigma_{t}}{\sigma_{t-1}}},
$$

where $z_{i}^{s}$ is the output level of commodity $i$ in zone $s$ and $\theta_{i}^{r}$ is a share parameter. $x_{i}^{r s}$ is input demand from zone $r$ required at zone $s$ in producing $i$.

We assume that firms minimize their cost with fixed output level $z_{i}^{s}$ as the constraint and take the trading cost in eqn.(1) as given. Formally, firms' behaviour is formulated as the following optimization program:

$$
\begin{gathered}
\min _{\left\{x_{i}^{r s}\right\}} \sum_{r \in R} x_{i}^{r s} p_{i}^{r s} \\
\text { s.t. }\left[\sum_{r \in R}\left(\theta_{i}^{r}\right)^{\frac{1}{\sigma_{t}}}\left(x_{i}^{r s}\right)^{\frac{\sigma_{t}-1}{\sigma_{t}}}\right]^{\frac{\sigma_{t}}{\sigma_{t-1}}}=z_{i}^{s}
\end{gathered}
$$


The optimization program yields the following demand equations for interzonal commodity flows

$$
x_{i}^{r s}=\frac{\theta_{i}^{r}\left(p_{i}^{r s}\right)^{-\sigma_{t}}}{\left[\sum_{r \in R} \theta_{i}^{r}\left(p_{i}^{r s}\right)^{1-\sigma_{t}}\right]^{\frac{\sigma_{t}}{\sigma_{t}-1}}} \cdot z_{i}^{s}
$$

and a unit cost function representing a composite purchase price at region $s, e . g$,

$$
q_{i}^{s}=\left[\sum_{r \in R} \theta_{i}^{r}\left(p_{i}^{r s}\right)^{1-\sigma_{t}}\right]^{\frac{1}{1-\sigma_{t}}} .
$$

Using eqn. (3), eqn. (4) is rewritten, for an unit output level at region s, in the following form:

$$
\tau_{i}^{r s}=\frac{x_{i}^{r s}}{z_{i}^{s}}=\frac{\theta_{i}^{r}\left(p_{i}^{r s}\right)^{1-\sigma_{t}}}{\sum_{r \in R} \theta_{i}^{r}\left(p_{i}^{r s}\right)^{1-\sigma_{t}}} \cdot \frac{q_{i}^{s}}{p_{i}^{r s}} .
$$

Finally, by assuming the iceberg specification for transport cost [9], we obtain the formula for interregional trade coefficients (ITC):

$$
T_{i}^{r s}=\tau_{i}^{r s}\left(1+\eta_{i}^{r s}\right)=\frac{\theta_{i}^{r}\left(p_{i}^{r s}\right)^{1-\sigma_{t}}}{\sum_{r \in R} \theta_{i}^{r}\left(p_{i}^{r s}\right)^{1-\sigma_{t}}} \cdot \frac{q_{i}^{s}}{p_{i}^{r}} .
$$

From the above equation, we also have the alternative expression for the composite purchase price:

$$
q_{i}^{s}=\sum_{r \in R} p_{i}^{r} T_{i}^{r s}
$$

From the definition of Chenery-Moses type of ITC [8], i.e.,

$$
\tilde{T}_{i}^{r s}=\frac{\tilde{x}_{i \cdot}^{r s}+\tilde{d}_{i}^{r s}}{\tilde{X}_{i}^{s}+\tilde{D}_{i}^{s}}=\frac{p_{i}^{r}}{q_{i}^{s}} \cdot \frac{\left(x_{i \cdot}^{r s}+d_{i}^{r s}\right)}{X_{i}^{s}+D_{i}^{s}}=\frac{p_{i}^{r}}{q_{i}^{s}} T_{i}^{r s}
$$

we can see that the ITC derived from the cost minimization program corresponds to quantity-based ITC. With the usage of those ITCs, the supply-demand relation for commodity $i$ at region $r$ can be expanded as

$$
\begin{aligned}
\tilde{X}_{i}^{r}=\sum_{s \in S}\left(\sum_{j \in C} \tilde{x}_{i j}^{r s}+\tilde{d}_{i}^{r s}\right) & =\sum_{s \in S} \tilde{T}_{i}^{r s}\left(\sum_{j \in C} \tilde{x}_{i j}^{s}+\tilde{D}_{i}^{s}\right) \\
& =\sum_{s \in S} T_{i}^{r s} \frac{p_{i}^{r}}{q_{i}^{s}}\left\{\sum_{j \in C}\left(\frac{q_{i}^{s}}{p_{j}^{s}} a_{i j}^{s}\right) p_{j}^{s} X_{j}^{s}+q_{i}^{s} D_{i}^{s}\right\} .
\end{aligned}
$$

Thus, we have the well-known supply-demand balancing equations:

$$
X_{i}^{r}=\sum_{s \in S} T_{i}^{r s}\left(\sum_{j \in C} a_{i j}^{s} X_{j}^{s}+d_{i}^{s}\right)
$$

With taking care that foreign trade is given by monetary-terms in the dataset, the supply-demand balancing systems in the closed economies are expanded to include exports $\tilde{E}_{i}^{r}$ and imports $\tilde{M}_{i}^{r}$ :

$$
p_{i}^{r} X_{i}^{r}=\sum_{s \in S} p_{i}^{r} T_{i}^{r s}\left(\sum_{j \in C} a_{i j}^{s} X_{j}^{s}+d_{i}^{s}\right)+\tilde{E}_{i}^{r}-\tilde{M}_{i}^{r}
$$


For the open economy, the above relations are rewritten using the rate of import $m_{i}^{r}$ as follows:

$$
p_{i}^{r} X_{i}^{r}=\sum_{s \in S} p_{i}^{r} T_{i}^{r s}\left(\sum_{j \in C} a_{i j}^{s} X_{j}^{s}+d_{i}^{s}\right)-p_{i}^{r} m_{i}^{r}\left(\sum_{j \in C} a_{i j}^{s} X_{j}^{s}+d_{i}^{s}\right)+\tilde{E}_{i}^{r}
$$

The nested structured ITC is necessary when we consider substation between regionally produced goods and imported goods. More general form of trade function is given as the following nested structure:

$$
\begin{gathered}
q_{i}^{s}=\left[\beta_{i}^{s}\left(p_{i}^{s}\right)^{1-\sigma_{t}}+\left(1-\beta_{i}^{s}\right)\left(q_{i}^{*_{s}}\right)^{1-\sigma_{t}}\right]^{1 /\left(1-\sigma_{t}\right)} \\
q_{i}^{*_{s}}=\left[\sum_{r \neq s} \theta_{i}^{r}\left(p_{i}^{r s}\right)^{1-\sigma_{t}}\right]^{1 /\left(1-\sigma_{t}\right)}
\end{gathered}
$$

and

$$
T_{i}^{*_{r s}}=\frac{\partial q_{i}^{*_{s}}}{\partial p_{i}^{r}}=\theta_{i}^{r}\left(1+\eta_{i}^{r s}\right)^{1-\sigma_{t}}\left(\frac{q_{i}^{*_{s}}}{p_{i}^{r}}\right)^{\sigma_{t}}, r \neq s
$$

where $\beta_{i}^{s}$ is the rate of regionally produced goods to the total inputs of commodity $i$ at region $s$. Final expression comes from Shephard's lemma [10].

\subsection{Spatial comparative advantage}

In input-output accounts at production price based, transport service required to produce a commodity for each firm is already embedded. In other words, production price of each firm includes transport cost. So we ignore the margin rate in eqn. (6). Suppose that a production price equal a purchase price for each commodity at any location, we have the relations, $T_{i}^{r^{r}}=\theta_{i}^{r}, \forall r, s \in R, i \in I$, from eqn. (6). Share parameters $\left\{\theta_{i}^{r}\right\}$ must be one-dimensional in location because of no information about interregional trade flows. Then, the share parameters are determined using the supply-demand balancing equations,(8). Instead of eqn. (6), let us assume the trade coefficients with two dimensional form of share parameter, $\left\{\varphi_{i}^{r s}\right\}$ :

$$
\begin{aligned}
& T_{i}^{r s}=\frac{\varphi_{i}^{r s}\left(p_{i}^{r}\right)^{1-\sigma_{t}}}{\sum_{r \in R} \varphi_{i}^{r s}\left(p_{i}^{r}\right)^{1-\sigma_{t}}} \cdot \frac{q_{i}^{s}}{p_{i}^{r}} \text { or } \\
& T_{i}^{r s}=\varphi_{i}^{r s}\left(\frac{q_{i}^{s}}{p_{i}^{r}}\right)^{\sigma_{t}}
\end{aligned} .
$$

Again, if we assume that $p_{i}^{r} \equiv q_{i}^{r}=1$, then we have $T_{i}^{r s}=\varphi_{i}^{r s}, \forall r, s \in R, i \in I$. Therefore, it can be regarded that the share parameter $\left\{\varphi_{i}^{r s}\right\}$ represents the economic potential or the spatial comparative advantage of location $r$ against location $s$. The spatial comparative advantage that each location has is considered to be intrinsically dependent on geographical configuration and be determined by the gravity law: 


$$
\begin{gathered}
\varphi_{i}^{r s}=\frac{\theta_{i}^{r}\left(X_{i}^{r}\right)^{\kappa_{i}}\left(c^{r s}\right)^{-\mu_{i}}}{\sum_{r \in R} \theta_{i}^{r}\left(X_{i}^{r}\right)^{\kappa_{i}}\left(c^{r s}\right)^{-\mu_{i}}} \\
\sum_{\mathrm{r}} \theta_{i}^{r}=1
\end{gathered}
$$

where $\left\{c^{r s}\right\}$ are interregional transport costs. Two dimensional share parameters are now decomposed into one dimensional ones, so that the share parameters $\left\{\theta_{i}^{r}\right\}$ can be calibrated using eqn. (8) even when no information about interregional trade flows is available. On the other hand, $\left\{\mu_{i}\right\}$ are parameters to be statistically estimated using other data sources. The purchase price (4) is also redefined along the line of this modification.

Weisbrod et al. [11] defined the shipping cost of a product by direct shipping cost and time variability cost, and associated the shipping time from zone $r$ to zone $s$ with the direct cost in dollars for each industry. Their approach is useful for estimation of transport cost: however, in this paper only the travel time between each origin-destination pair is taken into account as a sole component of transport cost and is applied to eq. (10).

\subsection{Labour market and the free-time}

A change in the physical network reduces congestion and brings about increase of the free-time, a portion of which will be supplied to labour service, thereby results in raise of income and utility level of the regions. Factor input $\mathrm{k}, f_{k}^{s}$, that is required in producing commodity $\mathrm{j}$ at location $\mathrm{s}, X_{j}^{s}$, is expressed by using value-added coefficients, $b_{k j}^{s}$, as:

$$
f_{k}^{s}=\sum_{j \in C} b_{k j}^{s} X_{j}^{s}
$$

On the other hand, labour supply is defined by

$$
\bar{f}_{L}^{s}=f_{0 L}^{s}+\omega f_{0 L}^{s} \frac{t_{0}^{s}-t^{s}}{t_{0}^{s}},
$$

where $\bar{f}_{L}^{s}$ and $f_{0 L}^{s}$ are labour supply and initial endowment at location $s$, respectively; $t_{0}^{s}, t^{s}$ are pre average travel time and post average travel time at location $s$. A parameter $\omega$ is a linear elasticity of labour supply with respect to the travel time that is estimated from time-budget survey. Capital inputs are assumed to be fixed.

\section{Economic impacts of Tokai ring road project}

The Tokai ring road is the projected expressway of about $160 \mathrm{~km}$ in length, which connects annularly many cities in Tokai region including Aichi, Gifu, and Mie prefectures, being located in the $30-40 \mathrm{~km}$ area of circumferences of Nagoya city. The construction of the expressway has already started and about half of which has already provided. It is expected to contribute to reducing travel 
congestion not only in the Tokai region but also in the transportation corridor between Tokyo and Osaka and bring in large economic benefits by forming a broad-based network together with other connected expressways.

\subsection{Benchmark equilibrium dataset}

We used the 2000 input-output tables of 47 prefectures with the following eight industrial sectors: 1. Primary (agriculture, fisheries and forestry), 2. Mining and Manufacturing, 3. Construction, 4. Public utilities, 5. Commercial, 6. Finance and Insurance, 7. Transport, 8. Services.

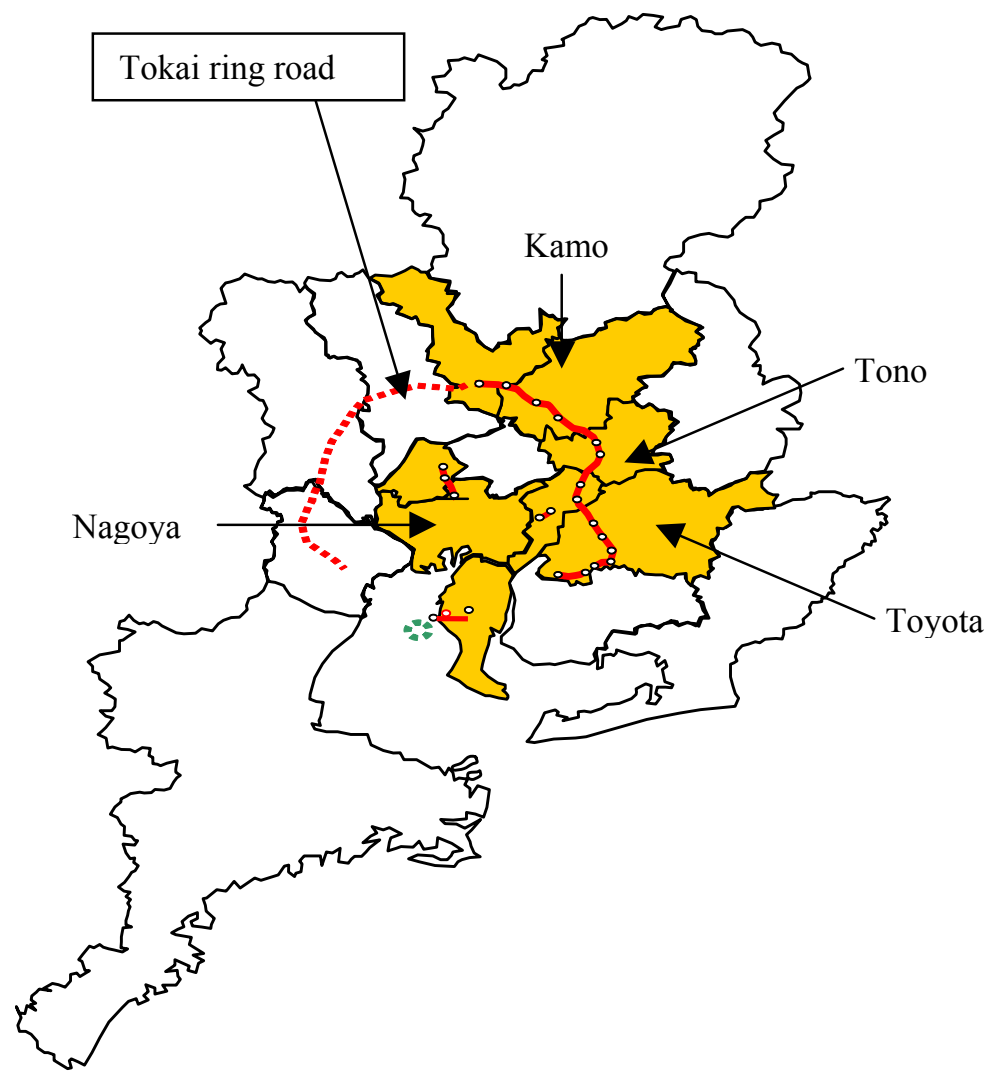

Figure 1: Zoning map in the Tokai region including Aich, Gifu and Mie prefectures, and Tokai ring road (real line indicates the completed portion of the project).

Figure 1 shows a zoning map of Tokai region together with Tokai ring road, in which the other areas are eliminated for space. As is shown in fig. 1, our target for impact assessment is the completed portion of the Tokai ring road and some 
other minor roads. In order to measure economic impacts arising from Tokai ring road, we divided Gifu and Aichi prefectures into several zones and Mie prefecture into two zones. For other prefectures included in central area of Japan, a single zone is associated with each prefecture and, for distant prefectures from the Tokai ring road, several prefectures were aggregated into a single zone and the total number of zone was 28. Input-output table corresponding to each zone was constructed and adjusted to make the benchmark equilibrium dataset consistent. M-SCGE was coded by GAMS language and CONOPT was used to solve the non-linear equation systems.

\subsection{Statistical estimation of parameters of the potential function}

Before carrying out calibration of the SCGE model, parameters included in the potential function should be statistically estimated. Interregional travel times were estimated using the user equilibrium traffic assignment, in which origindestination trip tables and trunk road network at the base year and the year 2020 were used, respectively. This work was performed in the other research project separately conducted from this study

\subsection{Results}

\subsubsection{Calibration}

Calibration was successfully completed; the original regional input-output tables were perfectly reproduced. Now that we have obtained the estimated interregional input-output table, the standard numerical calculation usually demonstrated in interregional input-output analysis becomes feasible at this stage.

\subsubsection{Scenario analysis}

Among the results that were obtained through with-without analysis, three main results are reviewed here.

1) The relationships between trade coefficients and travel time

Figure 2 shows a scatter diagram of the relative change in interregional commodity flows in manufacturing industry plotted against the relative change in the travel time. Although similar relationships as shown in this figure were obtained in other industries as well, manufacturing industry exhibited especially clear increasing returns in products in the sense that variance around a regression line is the least. This implies that decrease in congestion highly stimulates location change in this industrial sector. On the contrary, in primary industry including agriculture, fisheries and forestry, congestion-reduction effect on increasing returns of products was very weak, variance was the largest. In addition negative effects on production were observed, in almost all zone pairs where the relative change of travel time was less than ten percent. 
2) Impact on regional gross product

The Tokai area is an area where manufacturing industry is leading and strong in Japan, as represented by Toyota automobile company. Since the reduction in travel time gives a big change to the manufacturing industry as mentioned above, it is natural result that the Tokai beltway gave positive big impact to the Tokai overall community: especially the increase of production of the manufacturing industry in the Toyota area was largest. The second largest effect was observed in a service industry in Nagoya area, which includes Nagoya city, a core city of Tokai region. As far as relative change of RGP is concerned, however, the growth rate of RGPs in Kamo and Tono areas of Gifu prefecture through which the Tokai beltway passes showed maximum and the second largest values. The Tokai beltway which passes through these areas has already completed and it can be said that the numerical value shown here wears a touch of reality considerably from the fact that the industrial parks contiguous to the interchange have already fulfilled applications. On the contrary, remote areas from the Tokai beltway like Hokkaido, Kanto, Chyugoku, Shikoku and Kyusyu including Okinawa showed negative productions and RGPs. The total growth in production generated by the project was estimated to push 0.05 percent of the nation's production up.

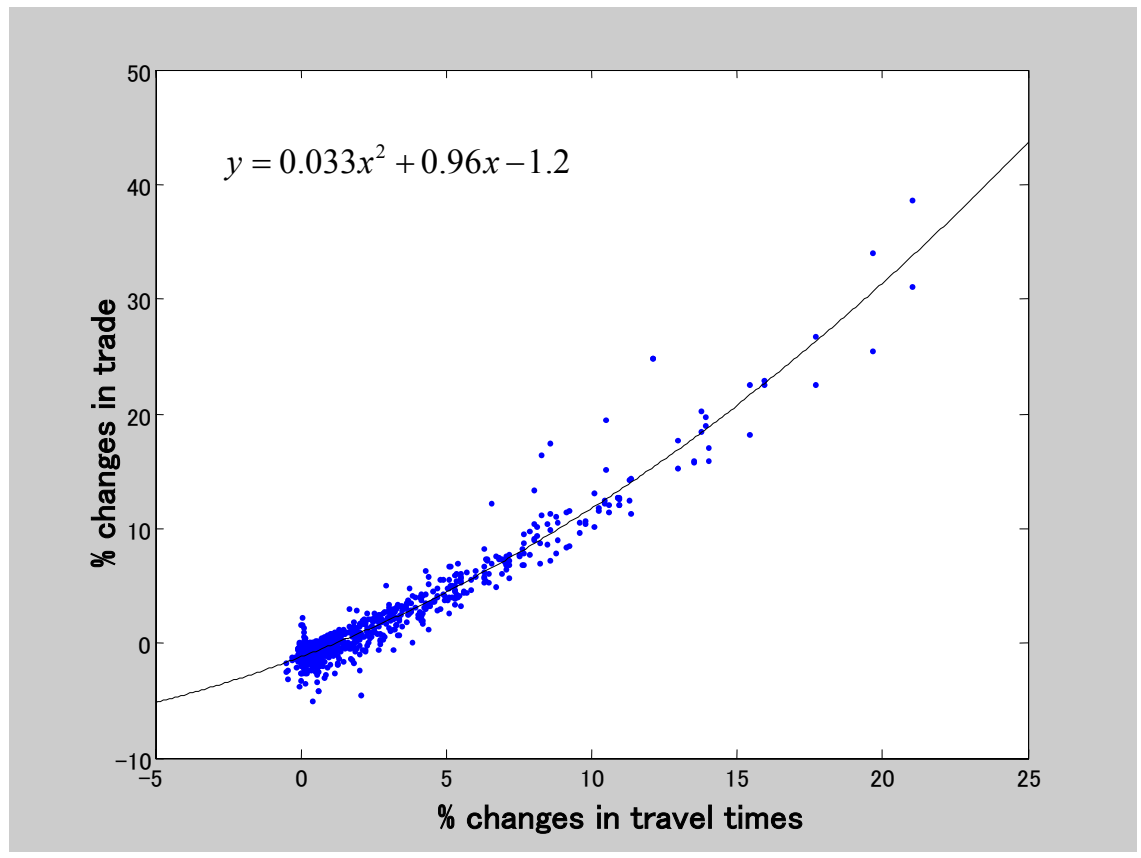

Figure 2: The relative change in interregional commodity flows (manufacturing) vs. the relative change in travel times. 


\section{3) Welfare effect}

The specification of the household demand system in the M-SCGE model allows the computation of measures of welfare. The Hicksian measures of equivalent variation and compensated variation [10] are regarded as appropriate benefit measures for evaluating public investment due to the assumption of the representative consumer [12]. The Hicksian measure of EV was 108 billion yen (about 0.92 billion US dollars). While the values of EV were positive in almost all zones in the Tokai region, the values of EVs in other zones exhibited negative.

\section{Concluding remarks}

A new feature of M-SCGE model is twofold. First, the concept of spatial comparative advantage was introduced to give economic interpretation about share parameters included in interregional trade function. This allows associating the changes in accessibility with the changes in transport cost and makes it possible to assess indirect economic impacts arising from the policies for reducing congestion. However, the issue associated with rigorous estimation method for parameters involved in the gravity model was not yet fully resolved and remained for future research. Although the results were not shown in this paper, we have applied a neural network algorithm to estimating those parameters and got good results. We observed through this study that estimation of the rate of regional trade was sensitive in predicting the growth rate of gross regional products. Therefore, estimation of intrazonal rate in trade through gravity model was recognized to be very important.

Secondly, we introduced a new elasticity parameter relating the increase of the free-time to the supply of labour service and the level of household's utility. The estimation of this parameter requires the time-budget survey.

Application results depend on some important parameters that are rarely observed from published data sources. In order to increase reliability of application results of SCGE model, it needs information exchanges among research communities.

\section{References}

[1] Miyagi, T., Construction of interregional input-output table at prefecture level and Applicability of SCGE model. Final Report, Scientific Research supported by grant-in-aid of the Ministry of Science and Education, 2005.

[2] Miyagi, T., and T. Sakurai, Calibration and Validation of a SCGE Model. CD-ROM Proc. of the $19^{\text {th }}$ Pacific Regional Science Conference, Tokyo, 2005.

[3] Miyagi, T., and Honbu K., An modelling of interregional trade based on spatial computable general equilibrium, Proc. of the 16th Annual Meeting on Infrastructure Planning and Management, No.16 (1)-2, pp.879-886,1993. 
[4] Miyagi, T., and Honbu K., An interregional trade model based on an applied general equilibrium, Journal of Infrastructure Planning and Management, JSCE, 530(IV-30), pp.31-40, 1996.

[5] Miyagi, T., K. Honbu and K. Inoue, Modelling of trade coefficients in multi-regional CGE model, Selected Proc of the Annual Meeting of Infrastructure Planning and Management, No. 15, pp.93-100, 1998.

[6] Bröcker, J., Operational spatial computable general equilibrium modeling, Ann. Reg. Sci. 32, pp.367-387, 1998.

[7] Haddad, E.A., and G.J.D. Hewings, Transport costs, increasing returns and regional growth: An interregional CGE analysis, CD-ROM Proc. of 2004 European Regional Conference, 2004.

[8] Hewings, G.J.D. and Jensen, R.C., Regional, interregional and multiregional input-output analysis, Handbook of Regional and Urban Economics, Vol. I, ed., P. Nijkamp, North-Holland, Amsterdam, 1986.

[9] Samuelson, P.A., Spatial price equilibrium and linear programming, American Economic Review, 42, pp. 283-303, 1952.

[10] Varian, H.R., Microeconomic Analysis (3rd edition), Norton, New York, 1992.

[11] Weisbrod, G., D. Vary and G. Treyz, Economic Implications of Congestion. NCHRP Report 463, National Academy Press, Washington, D.C., 2001.

[12] McKenzie, G.W., Measuring economic welfare. Cambridge University Press, Cambridge, NY, 1985. 